\title{
Prevalence unmet need for family planning and its associated factors in Ethiopia 2019: sytematic review and meta analysis
}

Temesgen Getaneh ( $\nabla$ temugetaneh@gmail.com )

Debre Markos University College of Health Science

\section{Ayenew Negesse}

Debre Markos university

\section{Tebabere Moltot}

Jigjiga University

Research article

Keywords: unmet need; family planning, Ethiopia

Posted Date: August 20th, 2019

DOl: https://doi.org/10.21203/rs.2.13220/v1

License: (c) (1) This work is licensed under a Creative Commons Attribution 4.0 International License.

Read Full License 


\section{Abstract}

Background unmet need for family planning is a common cuase of uninteded pregnancy which mostly end up with abortion. Many fragmented studies were conducted on unmet need in Ethiopia but no single evidence was present. So this meta analysis was established to estimate the pooled prevalence of unmet need for family planning in Ethiopia. Methods articles were retrived through search engines: PubMed/MEDLINE, EMBASE, CINAHL, Google Scholar, HINARI portal, and Cochrane Library using the preferred Reporting Items for Systematic Reviews and Meta-Analyses Protocols (PRISMA) checklist guidelines. Joanna Briggs Institute Meta-Analysis of Statistics Assessment and Review Instrument (JBIMAStARI) was applied for critical appraisal of included articles. Random effect model meta analysis was done to estimate the pooled prevalence of unmet need for family planning with their respective Odds Ratio (OR) and 95\% confidence interval (Cl). Cochran's Q statistic, Egger's and Begg's test and meta regression were carried out to assess heterogeneity, publication bias and to identify associated factors respectively. Results 15 articles and 17, 585 reproductive age women were included to estimate the polled prevalence of unmet need for family planning in Ethiopia. The pooled prevalence of unmet need for family planning in Ethiopia was $31.45 \%(95 \% \mathrm{Cl}$ : 26.52, 36.39). Age at first marriage < $18 \mathrm{yrs}$ with $\mathrm{OR}=2.3$ (95\% Cl: 1.08, 4.87), being illiterate women with OR= 0.9 (95\% Cl: 1.19, 3.04), illiterate partner with $\mathrm{OR}=1.78(95 \% \mathrm{Cl}: 1.18,2.68)$ and absence of discussion with their partner with $\mathrm{OR}=3.52(95 \% \mathrm{Cl}: 2.56$, 4.87) were the associated factors. Conclusion This meta analysis revealed the prevalence of unmet need for family planning in Ethiopia was high. Early marriage, illiteracy and absence of open discussion were factors affecting the prevalence of unmet ned for family planning. Therefore, the responsible body inlcuding family health guiadance should strength women empowerment interms of education (equal accessible eduaction for all), avoid early marriage (before 18yrs) and facilitate open partners discussion within house hold.

\section{Background}

Unmet need for family planning is the percentage of women of reproductive age, either married or in a union, who have an unmet need for family planning to stop or delay childbearing[1]. It shows the gap between childbearing desires and contraception use and taken as useful indicator towards the target of achieving universal access to reproductive health[2]. Early family planning was planned as a program to alleviate environmental, economic and societal impact of rapid population growth. But later run to help women and men to achieve their preferences and have their children when they want them as well play major role in maternal mortality reduction[3].

The Food and Drug Administration has approved a wide range of modern contraceptive including emergency contraceptives methods for preventing unintended pregnancy. But unintended or unplanned pregnancy is still the major incapacitating problem which affects million women and their families worldwide particularly in developing countries[4]. In 2017, around 800 million reproductive age pregnant 
women in developing countries wanted to avoid pregnancy from which an estimated 214 million women have an unmet need for family planning services. Globally $43 \%$ of unintended pregnancy occurred in developing world and $74 \%$ of them were related to unmet need for family planning while in East Africa unmet need for family planning responsible $86 \%$ unintended pregnancy[5].

Abortion is a frequent consequence of unintended pregnancy, an estimated 18 million unsafe abortions take place each year in the developing world and, can result in serious, long-term negative health effects including infertility and maternal death[6]. Fully meeting the unmet need for modern contraception would result in an estimated 76,000 fewer maternal deaths each year[7].

Although women are the primary focus of most of the services offered, it has impact on individual, interpersonal, familial and societal at large as well it has ramifications for healthy births and babies. Women with unmet need for spacing and limiting has elevated risk of under-five mortality for children[8]. Although unmet need are related to complex factors, range of constraints can prevent women from family planning service like demographic, socioeconomic factors and proximate factors[9-11].

Sub Saharan Africa has women with the highest number of unmet need for family planning as evidenced by $25 \%$ of reproductive age married or union women has unmet need for family planning[12]. So this is the reason why it share the highest burden of maternal mortality related to unwanted pregnancy and unsafe abortion than other regions.

Modern contraceptive use by currently married Ethiopian women has steadily increased. But still $22 \%$ of currently married women have an unmet need for family planning[13]. In Ethiopia different studies were conducted to assess prevalence of unmet need and associated factors [14-28]. The reports of these fragmented revealed a wide variability of prevalence of unmet need for family planning with the highest prevalence reported in South Nation and Nationality People region(SNNPR) (52.4\%)[23] while the lowest reported in Amhara region (17.4\%)[21]. Those studies also addressed some factors associated with the prevalence of unmet need for family planning; age, age at marriage, female and male education, discussion with partner and health care provider on family planning and occupation were considered as a common contributor to unmet need.

So these few findings in Ethiopia about prevalence of unmet need for family planning and associated factors indicated inconsistent and inconclusive results. Therefore, this meta-analysis and systematic review was conducted to estimate the pooled prevalence of unmet need for family planning and associated factors in Ethiopia.

\section{Methods}

\section{Search strategies}


This systematic review and meta-analysis was reported using the Preferred Reporting Items for Systematic Reviews and Meta-Analyses Protocols (PRISMA) checklist guidelines[29]. Published available studies were searched using international data bases; PubMed/MEDLINE, EMBASE, CINAHL, Google Scholar, HINARI portal (which includes the SCOPUS, African Index Medicus, and African Journals Online databases), and Cochrane Library. All studies conducted till June 10, 2019 were included in this review. "Prevalence of unmet need for family planning OR factors associated with unmet need for family planning AND Ethiopia" were used as a key word to search. Additionally articles found on local shelves and institutional repositories were considered. The references of already identified articles were also checked to dig out additional articles for this systematic review. Endnote citation manager software version $\mathrm{X} 7$ for Windows was utilized to collect and organize search outcomes and for removal duplicate articles.

\section{Inclusion criteria}

Population: studies conducted on reproductive age women were included.

Study area: the review considered only studies conducted in Ethiopia.

Language: articles reported in English language were eligible for this meta-analysis.

Observational studies (cross sectional, case control and cohort) which has clear outcome about unmet need for family planning were considered for final review. In addition, family planning was taken as an exposure and unmet need for family planning as final outcome.

\section{Exclusion criteria}

After careful reviewing those searched articles, irrelevant studies and those didn't report outcome of interest were excluded from this meta-analysis.

\section{Quality assessment}

Joanna Briggs Institute Meta-Analysis of Statistics Assessment and Review Instrument (JBI-MAStARI) [30] was applied for critical appraisal of included studies before data extraction. Random selection of the study sample, clear definition of the criteria for the inclusion of the sample in the study, identification and addressing for confounding factors, use of objective criteria to assess the outcome of interest, reliable measurement of outcome variable and use of appropriate statistical analysis method [30] were included in the appraisal tool.

\section{Data extraction}

Two authors (TG and AN) extract the data independently using the extraction tool developed according to Joanna Briggs Institute Reviewers' Manual 2014[30] based on potentially eligible criteria already settled. Authors, Region, study setting, study year, study design, sample size, response rate, participant's age, prevalence and common factors associated with unmet need for family planning were included in the 
extraction tool. Discrepancies between authors were discussed to reach consensus. For final analysis the authors considered articles which fulfilled the already settled criteria.

\section{Outcome of interest}

The primary outcome of this systematic and meta-analysis was the prevalence of unmet need for family planning. Unmet need for family planning is the percentage of women of reproductive age, either married or in a union, who have an unmet need for family planning to stop or delay childbearing[1]. The second outcome was factors associated with unmet need for family planning. Those factors extracted from included studies were; age of women ( $<25$ years $V_{S} \geq 25$ years), age at marriage ( $<18$ years $V_{S} \geq 18$ years), education (illiterate $V_{S}$ educated), occupation (house wife $V_{S}$ others) and discussion with partner (no discussion $\mathrm{V}_{\mathrm{S}}$ open partner discussions).

\section{Heterogeneity and publication bias}

Cochran's $Q$ statistic and inverse variance $\left(\mathrm{I}^{2}\right)$ for quantification with its corresponding $\mathrm{p}$-value using random effect model of analysis were considered to check heterogeneity. $I^{2}$ statistics of $25 \%, 50 \%$ and $75 \%$ was used to declare low, moderate and high heterogeneity respectively [31]. Heterogeneity was considered when p-value less than 0.05. In addition Egger's and Begg's tests were done to assess the presence of publication bias, and a p-value less than 0.05 were considered as statistically significance $[32,33]$.

\section{Statistical analysis}

Microsoft Excel spread sheet format was used to extract the selected articles. Then, extracted data were exported to STATA version 14 software for meta-analysis. For heterogeneity and publication bias assessment, Cochran's Q statistic and I (for quantification) and Egger's and Begg's tests and its corresponding p-value with random effect model (since it minimizes heterogeneity of the included studies [31] were considered. Comparison of original articles using tabulation was computed to assess some clinical or methodological heterogeneity even though always considered to be present (Table-1). The pooled prevalence of unmet need for family planning and its $95 \% \mathrm{Cl}$ were presented using forest plots. Factors associated with unmet need for family planning were computed and presented using forest plots with their respect of OR and $95 \% \mathrm{Cl}$. Subgroup analysis was also conducted by region of the study, study year, sample size and study setting of studies.

\section{Results}

\section{Article selection}

From electronic data base searching, 350 articles related to unmet need for family planning and associated factors were retrieved. From those records, 60 studies were removed after reviewing their titles due to duplication. Then after reviewing titles and abstracts of the remaining articles, 271 articles 
excluded because of irrelevance. Fifteen articles were assessed for eligibility and considered for the final review after 4 articles [34-37] removed due to inaccessibility of full articles even after email request for the full document till three times (Figure-1).

\section{Characteristics of included articles}

A total of 17, 585 reproductive age women were included in this meta-analysis to estimate the pooled prevalence of unmet need for family planning and associated factors in Ethiopia. All studies included were cross sectional and community based except two articles done at institution level[15, 27]. The majority of the included studies were conducted in Amhara region $[14,16,18,21,25,27]$ and the largest sample size was recorded in SNNPR[23](5746) whereas the smallest in Amhara region[27](337). From those studies the lowest prevalence of unmet need for family planning was reported in Amhara region[21] while the highest reported in SNNPR[23]. All included articles were conducted from 2009-2018 except one study manipulated in 2005[22]. In addition, almost all studies had a good response rate ( $\geq 97 \%)$ (Table1).

\section{Prevalence of unmet need for family planning in Ethiopia 2005-2018}

From those included studies ( 15 articles), the estimated pooled prevalence of unmet need for family planning in Ethiopia was $31.45 \%$ (95\% Cl: 26.52, 36.39). The lowest prevalence was observed in Amhara region[21] (17.4\%, 95\% Cl: 11.80, 23.00) while the largest recorded in SNNPR[23] (52.4\%, 95\%Cl: 44.64, 60.16). The included studies showed substantial heterogeneity $\left(I^{2}=88, P=0.000\right)$ indicated to compute random effect meta-analysis. So, to identify possible source of heterogeneity univariate meta regression model analysis using different factors like Region, study setting and study year was computed, but none of them were significant. However, publication bias was non-significant using Begg's and Egger's test $(p=0.458$ and $p=0.258$ respectively) (Figure- 2 ).

\section{Sub group analysis}

Subgroup analysis was performed to compare the prevalence of unmet need for family planning using study year, sample size, region and study setting. The subgroup analysis by region showed the highest prevalence of unmet need for family planning in SNNPR, 39.5\% (95\% Cl: 28.15, 50.85) and the lowest in others (include Oromo and AA), $27.40 \%(95 \% \mathrm{Cl}: 16.34,38.47)$. The prevalence of unmet need for family planning before the year 2014 was $34.49 \%(95 \% \mathrm{Cl}: 24.92,44.06)$ and it reduces to $29.03 \%(95 \% \mathrm{Cl}: 23.44$, 34.62) after 2014. The prevalence of unmet need for family planning conducted on community based was $32.09 \%(95 \% \mathrm{Cl}: 24.50,39.68)$ which was almost in line with studies conducted at institution based, $31.65 \%$ (95\% Cl: $19.94,37.58)$. In relation to sample size the pooled prevalence of unmet need for family planning with sample size $<614$ was $30.5 \%(95 \% \mathrm{Cl}: 22.73,38.28)$ whereas sample size 614 and above the polled prevalence was $32.6 \%$ (95\%Cl: 22.73, 42.47) (Table-2). 


\section{Meta regression}

In order to identify factors associated with source of heterogeneity of the pooled prevalence of unmet need for family planning, meta regression was undertaken by considering both continuous and categorical data. Sample size, study year, study setting and region for each individual studies were considered in the meta-regression. But the meta regression showed that the pooled prevalence of unmet need for family planning was not associated with sample

\section{Factors associated with unmet need for family planning}

As shown below in figure-3, we tried to investigate factors associated with unmet need for family planning. Age of the women, age at first marriage, education level of both women and their partner, discussion with partner and occupation were factors assessed for association. But only age at first marriage, education level (both) and discussion were significantly associated with unmet need for family planning. Age at first marriage was reported in three articles $[16,18,20]$. Women with age at first marriage $<18 y$ rs were 2.3 times more likely to have unmet need for family planning than women marriage at $18 y$ rs and above, OR=2.3 and $(95 \% \mathrm{Cl}: 1.08,4.87)$. Level of female education was another factor recorded in eight articles $[14,16-18,20,21,24,27]$. The odds of unmet need for family planning was 1.9 times higher in illiterate women than literate women (read and write, primary and above educational level), $\mathrm{OR}=0.9$ and $(95 \% \mathrm{Cl}: 1.19,3.04)$. The association between male partner education and unmet need for family planning was reported in four articles $[16,18,23]$. The likely hood of unmet need for family planning in women with illiterate male partner was 1.78 times higher than women having literate male partner, $\mathrm{OR}=1.78$ and $(95 \% \mathrm{Cl}: 1.18,2.68)$. The last but not the least factor, which was associated with unmet need for family planning was discussion, reported in six original articles[14, 16-18, 24, 25]. Women with no discussion with her partner about family planning were 3.52 times more likely to have unmet need for family planning when compared with women with pertinent discussion with partner, $\mathrm{OR}=3.52$ and $(95 \% \mathrm{Cl}$ : $2.56,4.87$ ). The other two factors (age less than $25 y$ rs and occupation of women-being house wife) were not significantly associated with unmet need for family planning, $\mathrm{OR}=1.16$ and $(95 \% \mathrm{Cl}: 0.65,2.08)$ and $\mathrm{OR}=2.07$ and $(95 \% \mathrm{Cl}: 0.78,5.52)$ respectively (figure-3).

\section{Discussion}

This systematic review and meta-analysis was computed to estimate the pooled prevalence of unmet need for family planning and associated factors in Ethiopia. We found higher prevalence of unmet need for family planning in Ethiopia with overall prevalence of $31.45 \%(95 \% \mathrm{Cl}: 26.52,36.39)$. This higher prevalence of unmet need in Ethiopia is due to fertility related reasons (breast feeding and postpartum amenorrhea), lack of knowledge on family planning (women had no knowledge of a source for method and didn't know of a method), opposition to use (either from respondents, husbands or religious prohibition) and health concerns (including side effects) $[18,21,38]$. To address the issue of unmet need promptly and to identify program options, it is imperative to examine this issues that are responsible for the nonuse of family planning methods among women. 
This finding is in line with research conducted in Saudi Arabia, which reported the prevalence of unmet need for family planning as 32.6\%[39]. In the other hand our finding was lower than studies conducted in India and Eastern Sudan, which showed the prevalence of unmet need for family planning as $40.6 \%$ and $44,8 \%$ respectively $[40,41]$. However this result is much higher than studies conducted in Egypt and Cameroon, which reported the prevalence of unmet need for family planning as $11.2 \%$ and $20.4 \%[42,43]$. Our meta-analysis also tried to investigate factors associated with unmet need for family planning. Age at marriage $<18 y$ rs, illiteracy and absence of discussion between partners were factors significantly affecting the prevalence of unmet need for family planning.

Those women married before 18yrs were 2.3 times more likely to have unmet need for family planning than women married after 18yrs. This may be due to as age increase independency and decision to family size increase in line with maturity and awareness. Age is the major determinant for acquiring knowledge and gathering information through different contacting and communication ways (lower age group have restricted communication issues). So it affects the woman's ability to make her own decision regarding the reproductive health.

The odds of unmet need for family planning among illiterate women was 1.9 times higher when compared with women having education or literate ones. This finding is in agreement with study conducted in Saudi Arabia and Nigeria, reported as women with no education had higher odds of unmet need[39, 44]. In addition to this, those women with partner illiterate was 1.78 times more likely to have unmet need for family planning than women with educated partners. This is also consistent with finding in Eastern Sudan, lower level of husband's education negatively affect utilization of family planning[41]. Education is the major tool to increase awareness level and better access for information in family planning so as desire for post-pone fertility. Women should be adequately empowered in education so as to improve knowledge and awareness of methods and sources of contraceptives which has been found as a major barrier to contraceptive use.

This review also showed that discussion with sexual partner was significantly associated with unmet need for family planning. Women who didn't have discussion with their sexual partner about family planning were 3.52 times more likely to have unmet need for family planning when compared with women having discussion with their sexual partner on family planning service. This association is line with finding reported in Cameroon, discussion

about family planning within the couple had highly statistically significant protective association with unmet need[43]. This may be due to that women who had partner support and clear decision on family planning will have good attitude and initiative to contraceptive. Therefore women involvement in decision particularly that affect their health status is very important. As this review reported both the pooled prevalence unmet need for family planning and associated factors, it is important for policy makers to investigate the gaps on those factors.

\section{Limitations}


This review includes articles reported only in four regions and one administrative city, so didn't include all regions and administrative cities. Those articles included in this systematic review and meta-analysis were conducted in cross sectional study design in which the finding might potentially affected by confounding variables. In addition the review analyzed only studies reported in English language which might restrict our findings. Finally we like to recommend for researchers to conduct country based studies to assess other confounding factors related to health policy and service factors for the prevalent unmet need for family planning in Ethiopia.

\section{Conclusions}

The prevalence of unmet need for family planning in Ethiopia was high. Age at marriage < 18yrs, illiteracy (both women and their partner) and absence of discussion with their partner were factors significantly associated with unmet need for family planning. Therefore, Minister of Health and family guidance with their stake holders should emphasis on community and based programs to alleviate those factors leading to prevalent unmet need for family planning.

\section{Abbreviations}

AA-Addis Ababa, SNNPR-South Nation and Nationality peoples Region

\section{Declarations}

\section{Acknowledgments}

Not applicable.

\section{Funding}

No funding was obtained for this study.

\section{Availability of data and materials}

Data will be available from the corresponding author upon reasonable request.

\section{Authors' contributions}

TG developed the protocol and involved in the design, selection of study, data extraction, statistical analysis and developing the initial drafts of the manuscript. TG and AN involved in quality assessment. TG, AN and TM prepared and revising subsequent drafts as well as prepared the final draft of the manuscript. All authors read and approved the final draft of the manuscript.

\section{Ethics approval and consent to participate}

Not applicable.

\section{Consent for publication}

Not applicable.

\section{Competing interests}


The authors have declared that there are no competing interests.

\section{Publisher's Note}

Springer Nature remains neutral with regard to jurisdictional claims in published maps and institutional affiliations.

\section{Author details}

${ }^{1}$ Department of Midwifery, College of Health Science, Debre Markos University, P.O BOX 269, Debre Markos, Ethiopia

${ }^{2}$ Department of Nutrition, College of Health Science, Debre Markos University, Debre Markos, Ethiopia

${ }^{3}$ Department of Midwifery, College of Health Science, Debre Birhan University, Debre Birhan, Ethiopia

\section{References}

1. United Nations, Department of Economic and Social Affairs, Population Division. World Contraceptive Use 2014.

2. Alkema L, Kantorova V, Menozzi C, Biddlecom A: National, regional, and global rates and trends in contraceptive prevalence and unmet need for family planning between 1990 and 2015: a systematic and comprehensive analysis. The Lancet 2013, 381(9878):1642-1652.

3. Megan LK, Ragnar MA: Contraception and Beyond: The Health Benefits of Services Provided at Family Planning Centers. Guttmacher Institute 2013.

4. Michelle JH, Amanda MK, Terri-Ann T, Ushma DU: Interventions to Prevent Unintended and Repeat Pregnancy Among Young People in Low- and Middle-Income Countries: A Systematic Review of the Published and Gray Literature. Journal of Adolescent Health 2016:58-515.

5. Darroch JE, Audam S, Biddlecom A: Adding It Up: Investing in Contraception and Maternal and Newborn Health, 2017-Supplementary Tables. New York, NY: The Guttmacher Institute 2017.

6. John S, William W: The effects of family planning and other factors on fertility, abortion, miscarriage, and stillbirths in the Spectrum model. BMC Public Health 775 Page 44 of 15 2017, 17(4).

7. Tizta TD: Why family planning matters for maternal deaths and child survival. 2017.

8. Adedini SA, Odimegwu C, Imasiku EN, Ononokpono DN: Unmet need for family planning: implication for under-five mortality in Nigeria. Journal of health, population, and nutrition 2015, 33(1):187.

9. Bradley SE, Croft TN, Fishel JD, Westoff CF: Revising unmet need for family planning. 2012.

10. MacQuarrie K: Unmet need for family planning among young women: levels and trends. 2014.

11. Ajmal S, Idris A, Ajmal B: Factors affecting contraceptive use and unmet need among currently married women in Afghanistan: further analysis of the 2015 Afghanistan Demographic and Health Survey. Journal of Global Health Reports 2018, 2. 
12. United Nations Department of Economic and Social Affairs, Population Division. Meeting Demand for Family Planning. Population facts. No. 2013/6 December 2013. . 2013.

13. FDRE: ETHIOPIA Demographic and Health Survey 2016. 2017.

14. Tegegn M, Arefaynie M, Tiruye TY: Unmet need for modern contraceptives and associated factors among women in the extended postpartum period in Dessie town, Ethiopia. Contraception and reproductive medicine 2017, 2(1):21.

15. Mota K, Reddy S, Getachew B: Unmet need of long-acting and permanent family planning methods among women in the reproductive age group in shashemene town, Oromia region, Ethiopia: a cross sectional study. BMC women's health 2015, 15(1):51.

16. Biadgie A, Nigusie A, Handebo S: Prevalence and Associated Factors of Unmet Need for Family Planning Among Married Women in Rural Communities of Gonji Kollela District, North West Ethiopia: Cross-Sectional Study. J Fam Med Forecast 2019; 2 (1), 1015.

17. Chafo K, Doyore F: Unmet need for family planning and associated factors among currently married women in Misha District, Southern Ethiopia: A cross sectional study. J Women's Health Care 2014, 3(165):2167-0420.1000165.

18. Dejenu G, Ayichiluhm M, Abajobir AA: Prevalence and Associated Factors of Unmet need for Family Planning among Married Women in Enemay District, Northwest Ethiopia: A Comparative CrossSectional Study. Global Journal of Medical Research 2013.

19. Deyessa N, Argaw A: Intimate partner violence and unmet need for contraceptive use among Ethiopian women living in marital union. Ethiopian Journal of Health Development 2018, 32(3).

20. Gebre G, Birhan N, Gebreslasie K: Prevalence and factors associated with unmet need for family planning among the currently married reproductive age women in Shire-Enda-Slassie, Northern West of Tigray, Ethiopia 2015: a community based cross-sectional study. Pan African Medical Journal 2016, 23(1).

21. Genet $\mathrm{E}$, Abeje G, Ejigu T: Determinants of unmet need for family planning among currently married women in Dangila town administration, Awi Zone, Amhara regional state; a cross sectional study. Reproductive health 2015, 12(1):42.

22. Hailemariam A, Haddis F: Factors affecting unmet need for family planning in southern nations, nationalities and peoples region, Ethiopia. Ethiopian journal of health sciences 2011, 21(2):77-90.

23. Mekonnen W, Worku A: Determinants of low family planning use and high unmet need in Butajira District, South Central Ethiopia. Reproductive Health 2011, 8(1):37.

24. Shifa GT, Kondale M: High unmet need for family planning and factors contributing to it in southern Ethiopia: A community based cross-sectional study. Global Journal of Medical Research 2014.

25. Worku SA, Ahmed SM, Mulushewa TF: Unmet need for family planning and its associated factor among women of reproductive age in Debre Berhan Town, Amhara, Ethiopia. BMC research notes 2019, 12(1):143.

26. Yibrah HG, Gabriel TW: Explaining Unmet Need for Family Planning in Rural Tigrai, Ethiopia. . Journal of Contraceptive Studies 2018, 3(2):14. 
27. Tessema AL, Bishaw MA, Bunare TS: Assessment of the magnitude and associated factors of unmet need for family planning among women of reproductive age group with disabilities in Bahir Dar City, Amhara Region, North West Ethiopia. Open Journal of Epidemiology 2015, 5(01):51.

28. Kidane G, Brhane G, Abebaw G, Hailay S, Gizienesh K, Mebrahtu A: Unmet need for modern contraception and associated factors among reproductive age group women in Eritrean refugee camps, Tigray, north Ethiopia: a cross-sectional study. BMC Research Notes 2018, 11:851.

29. Moher D, Liberati A, Tetzlaff J, Altman DG, Group P: Reprint-preferred reporting items for systematic reviews and meta-analyses: the PRISMA statement. Physical therapy 2009, 89(9):873-880.

30. Munn Z, Moola S, Lisy K, Riitano D: The Joanna Briggs institute reviewers' manual 2014. The systematic review of prevalence and incidence data Adelaide, SA: The Joanna Briggs Institute 2014.

31. Higgins JP, Thompson SG, Deeks JJ, Altman DG: Measuring inconsistency in meta-analyses. Bmj 2003, 327(7414):557-560.

32. Begg $\mathrm{CB}$, Mazumdar M: Operating characteristics of a rank correlation test for publication bias. Biometrics 1994:1088-1101.

33. Egger M, Smith GD, Schneider M, Minder C: Bias in meta-analysis detected by a simple, graphical test. Bmj 1997, 315(7109):629-634.

34. Ashenafi G: Assessment of unmet need for family planning and factors influencing modern contraceptive utilization among women of reproductive age group in Girar Jarso District, North Shoa Zone, Oromia National Regional State, Ethiopia. Addis Ababa University 2011.

35. Mihret N: Determinants of unmet need for contraception among currently married couples in west belessa woreda. North gondar of amhara, Ethiopia 2008.

36. Molla $\mathrm{G}$, Belete $\mathrm{H}$ : Unmet need for family planning and its determinants among currently married women in Kobbo woreda, North-East of Amhara. Ethiopian Journal of Reproductive Health 2011, $5(1)$.

37. Sahele S: Assessment of the Magnitude and Determinants of Unmet Need for Family Planning among Currently Married Women in Urban and Periurban Community in Hawassa, Southern Ethiopia. . Ethiopia Journal of health Science 2003, 21:68-70.

38. Antenane K: Attitudes toward Family Planning and Reasons for Nonuse among Women with Unmet Need for Family Planning in Ethiopia. Calverton, Maryland USA: ORC Macro 2002.

39. Khalil SN, Alzahrani MM, Siddiqui AF: Unmet need and demand for family planning among married women of Abha, Aseer Region in Saudi Arabia. Middle East Fertility Society Journal 2018, 23(1):3136.

40. Begum S, Nair S, Donta B, Prakasam C: Prevalence of unmet need for contraception in urban slum communities, Mumbai. Int J Reprod Contracept Obstet Gynecol 2014, 3(3):627-630.

41. Abdel AAA, Amira O: Factors affecting unmet need for family planning in Eastern Sudan. BMC Public Health 2013, 13:102. 
42. Ragaa E-M, Noha E, Ghoneim M: Unmet need for family planning among women in rural Egypt. International Journal of Community Medicine and Public Health 2018, 5(4):1252.

43. Atem BA, Philip NN, Martin NY, Marie JE, Felix E, Filbert EE, Bruno K, Enow RM: Determinants of unmet need for family planning among women in Urban Cameroon: a cross sectional survey in the Biyem-Assi Health District, Yaoundé. BMC Women's Health 2016, 16:4.

44. Fagbamigbe AF, Afolabi RF, Idemudia ES: Demand and unmet needs of contraception among sexually active in-union women in Nigeria: distribution, associated characteristics, barriers, and program implications. SAGE Open 2018, 8(1):2158244017754023.

\section{Tables}

Table 1; Descriptive summary of eleven studies included in the meta-analysis of unmet need for family planning and associated factors in Ethiopia 2005-2018

\begin{tabular}{|l|l|l|l|l|l|l|}
\hline Author name & $\begin{array}{l}\text { Study } \\
\text { year }\end{array}$ & Region & $\begin{array}{l}\text { Study } \\
\text { setting }\end{array}$ & $\begin{array}{l}\text { Sample } \\
\text { size }\end{array}$ & $\begin{array}{l}\text { Prevalence } \\
(\%)\end{array}$ & Quality score \\
\hline Biadgie et al[16] & 2015 & Amhara & Community & 614 & 23.8 & 7 \\
\hline Gebre et al[20] & 2015 & Tigray & Community & 510 & 21.4 & 7 \\
\hline Dejenu et al[18] & 2013 & Amhara & Community & 755 & 25.6 & 6 \\
\hline Shifa et al[24] & 2010 & SNNPR & Community & 809 & 41.5 & 9 \\
\hline Mota et al[15] & 2012 & Oromo & Institution & 366 & 33.3 & 8 \\
\hline Deyessa et al[19] & 2016 & AA & Community & 2810 & 22 & 7 \\
\hline Worku et al[25] & 2018 & Amhara & Community & 411 & 30.9 & 8 \\
\hline Mekonnen et al[23] & 2009 & SNNPR & Community & 5746 & 52.4 & 6 \\
\hline Yibrah et al[26] & 2014 & Tigray & Community & 1240 & 31.5 & 7 \\
\hline Tessema et al[27] & 2013 & Amhara & Institution & 337 & 24.3 & 6 \\
\hline Genet et al[21] & 2014 & Amhara & Community & 556 & 17.4 & 6 \\
\hline Chafo et al[17] & 2013 & SNNPR & Community & 660 & 26.5 & 8 \\
\hline Tegegn et al[14] & 2014 & Amhara & Community & 383 & 45.2 & 7 \\
\hline Hailemariam et al[22] & 2005 & SNNPR & Community & 1988 & 37.4 & 9 \\
\hline $\begin{array}{l}\text { Gebrecherkos et } \\
\text { al[28] }\end{array}$ & 2016 & Tigray & Community & 400 & 41.8 & 7 \\
\hline
\end{tabular}

Table 2Sub group analysis which describes pooled prevalence of unmet need for family planning and its predictors in Ethiopia from 2005-2018 


\begin{tabular}{|l|l|l|l|l|l|l|}
\hline Subgroup & & No of studies & prevalence (95\%ci) & Heterogeneity statistics & $\mathrm{I}^{2}$ & $\mathrm{p}$-value \\
\hline \multirow{4}{*}{ Region } & Amhara & 6 & $27.71(21,34)$ & 92.23 & 94.6 & $<0.001$ \\
\cline { 2 - 7 } & Tigray & 3 & $31.44(21,41)$ & 46.58 & 95.7 & $<0.001$ \\
\cline { 2 - 7 } & SNNPR & 4 & $39.50(28,50)$ & 292.64 & 99.0 & $<0.001$ \\
\cline { 2 - 7 } & Others & 2 & $27.40(16,38)$ & 19.12 & 94.8 & $<0.001$ \\
\hline \multirow{3}{*}{ Study year } & Before 2104 & 7 & $34.49(24,44)$ & 522.50 & 98.9 & $<0.001$ \\
\cline { 2 - 7 } & 2014 \& above & 8 & $29.03(23,34)$ & 181.45 & 96.1 & $<0.001$ \\
\hline \multirow{3}{*}{ Study setting } & community & 13 & $32.09(24,39)$ & 1304.73 & 99.1 & $<0.001$ \\
\cline { 2 - 7 } & Institution & 2 & $28.76(19,37)$ & 7.03 & 85.8 & $<0.001$ \\
\hline \multirow{2}{*}{ Sample size } & $<614$ & 7 & $30.50(22,38)$ & 142.37 & 95.8 & $<0.001$ \\
\cline { 2 - 7 } & $\geq 614$ & 8 & $32.60(22,42)$ & 1085.64 & 99.4 & $<0.001$ \\
\hline
\end{tabular}

size, study year, study setting and region of study (Table-3).

Table 3Meta regression for the included studies to identify source of heterogeneity for the prevalence of unmet need for family planning in Ethiopia from 2005 up to 2018

\begin{tabular}{|c|l|l|}
\hline Variables & Coefficients & p-value \\
\hline Study year & -1.415 & 0.093 \\
\hline Sample size & 0.0032 & 0.084 \\
\hline Study setting & & \\
\hline Institution based & -3.292 & 0.689 \\
\hline Community based & Reference & Reference \\
\hline Region & & \\
\hline Amhara & Reference & Reference \\
\hline SNNPR & 11.768 & 0.090 \\
\hline Tigray & 3.711 & 0.605 \\
\hline Others & -0.268 & 0.974 \\
\hline
\end{tabular}

\section{Figures}




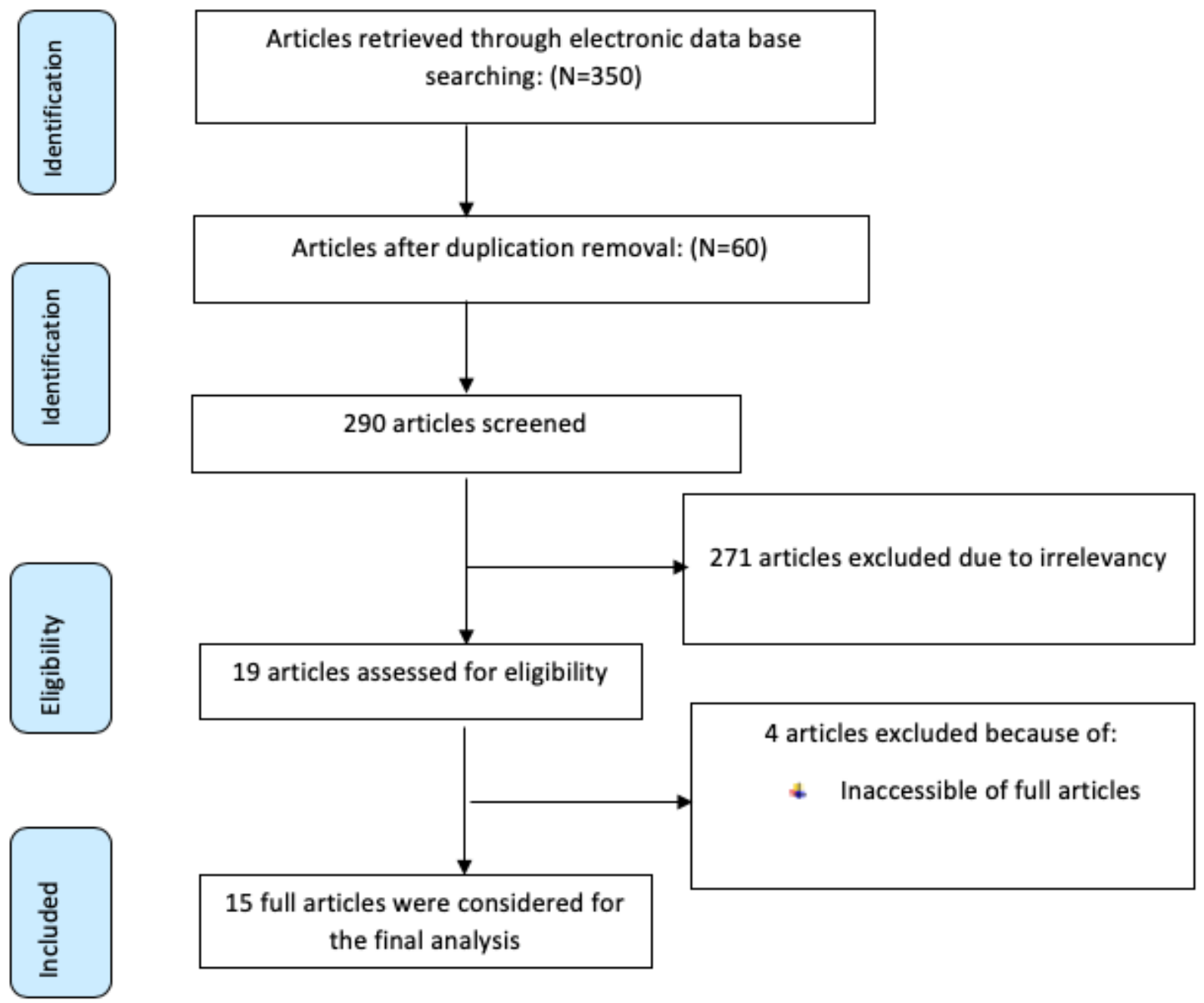

Figure 1

PRISMA flow diagram of included studies to estimate the pooled prevalence of unmet need for family planning and associated factors in Ethiopia 2005-2018 


\begin{tabular}{l} 
Study \\
ID \\
\hline Biadgie et al (2015) \\
Gebre et al (2015) \\
Dejenu et al (2013) \\
Shifa et al (2010) \\
Mota et al (2012) \\
Deyessa et al (2016) \\
Worku et al (2018) \\
Mekonnen et al (2009) \\
Yibrah et al (2014) \\
Tessema et al (2013) \\
Genet et al (2014) \\
Chafo et al (2013) \\
Tegegn et al (2014) \\
Hailemariam et al (2005) \\
Gebrecherkos et al (2016) \\
Overall (l-squared =88.0\%, p=0.000) \\
NOTE: Weights are from random effects analysis
\end{tabular}

Figure 2

Forest plot of the pooled prevalence of unmet need for family planning in Ethiopia 2005-2018 


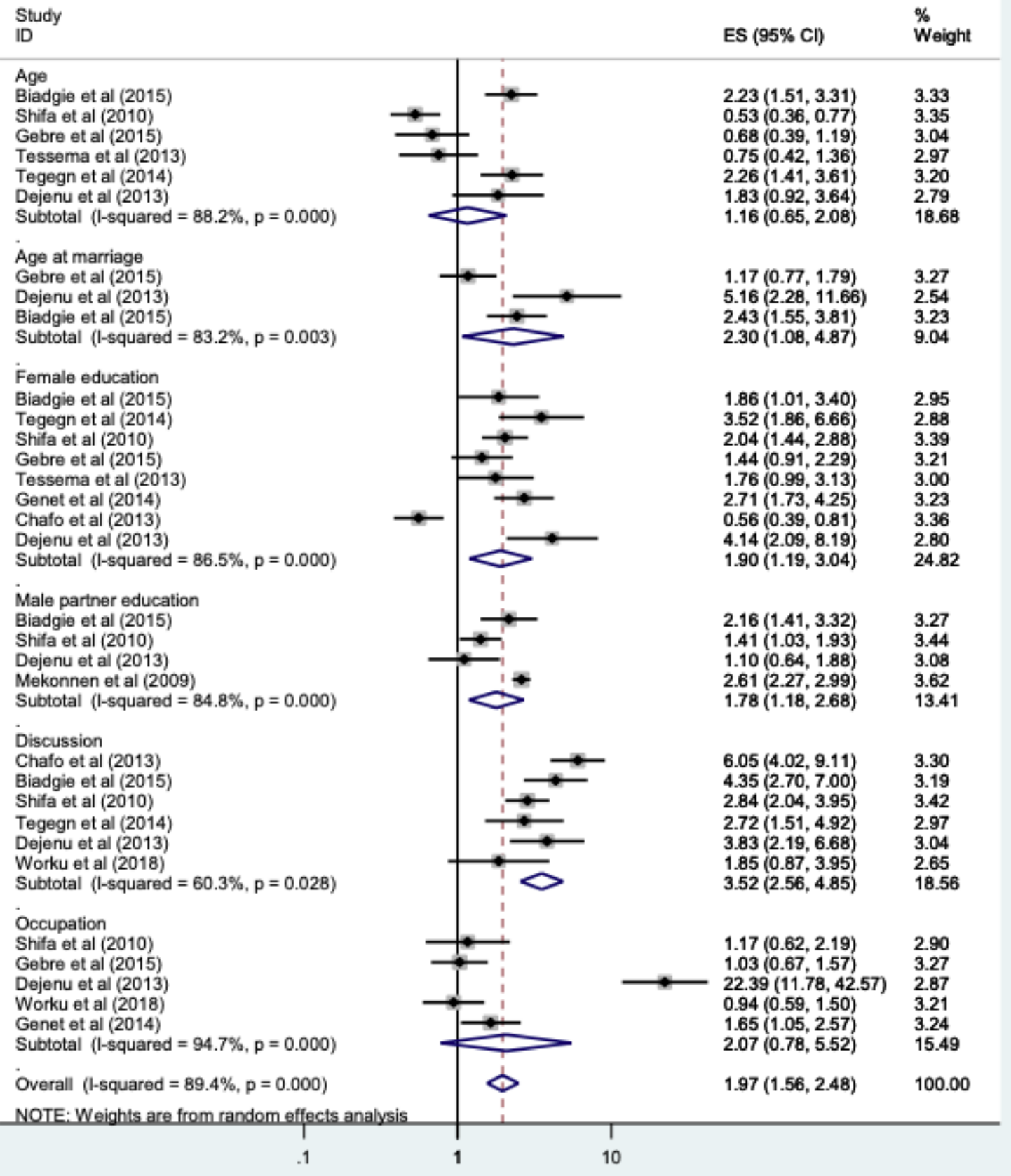

\section{Figure 3}

Forest plots which describe factors associated with unmet need for family planning in Ethiopia 20052018 